\title{
Efeito da antecedência de compra nas variações de preço das passagens aéreas: o caso da região metropolitana de São Paulo
}

[Effects of advanced purchase on tickets price variation: the case of the São Paulo metropolitan area]

\author{
Marcus Vinícius Nascimento*
}

Instituto Tecnológico de Aeronáutica (ITA), Brazil

Submitted 1 Nov 2011; received in revised form 15 Dec 2011; accepted 26 Jan 2012

\begin{abstract}
Resumo
O objetivo deste artigo concentra-se em avaliar se existem variações na prática de descontos das passagens aéreas compradas com antecedência entre os voos regionais e ponte aérea e entre voos na alta e na baixa estação. Com o auxílio de um modelo econométrico e com a coleta de dados em um período de três anos $(2008,2009$ e 2010) de voos com origem nos aeroportos de Guarulhos e Congonhas, foi observado que a antecedência de compra para voos de ponte aérea reflete em desconto médio de $37 \%$, enquanto para os voos regionais o desconto observado é de $24.3 \%$. Na alta estação os voos passam a ter maiores descontos, em relação à baixa, a partir de compras com antecedência de 30 dias da data do voo. A principal explicação para os resultados pode ser embasada na segmentação entre os passageiros que viajam a negócio e a lazer.
\end{abstract}

Palavras-Chave: companhias aéreas; passagens aéreas; aeroportos.

\section{Abstract}

This paper focuses on evaluate whether there are variations in the practice of discount in advanced airline fare purchase in regional and airlift flights and flights between the high and low season. With the aid of an econometric model and a data collection over a period of three years $(2008,2009$ and 2010) of flights with origin from Guarulhos and Congonhas airports, it was observed that the advance purchase for airlift flights reflected in average discount of $37 \%$, while for regional flights the discount of $24.3 \%$ is observed. . In relation with low season, the high season flights have larger discounts just after purchase with 45 days from the flight date. The main explanation for the results can be grounded in segmentation between passengers who travel for business and leisure.

Key words: airlines; airlines fares; airports.

*Email: mvn.marcus@gmail.com.

\section{Recommended Citation}

Nascimento, M. V. (2012) Efeito da antecedência de compra nas variações de preço das passagens aéreas: o caso da região metropolitana de São Paulo. Journal of Transport Literature, vol. 6, n. 3, pp. 49-59.

- JTL/RELIT is a fully electronic, peer-reviewed, open access, international journal focused on emerging transport markets and published by BPTS - Brazilian Transport Planning Society. Website www.transport-literature.org. ISSN 2238-1031. 


\section{Introdução}

Pesquisas realizadas por agências especializadas como a ANAC (2010) e a Infraero (2010) demonstram uma popularização do transporte aéreo no Brasil, fato que resulta e um aumento significativo da demanda pelo modal aéreo, principalmente na última década. Muito deste fenômeno pode ser reflexo das entradas de companhias aéreas low-cost no mercado nacional, como a Gol em 2001 e a Azul em 2009, que contribuíram com o efeito de redução nos preços das passagens aéreas nas rotas nacionais.

A contribuir com este cenário, a desregulação do mercado aéreo nacional, retomada na década de 2000, viabiliza a prática do yield management pelas companhias aéreas. O yield management refere-se à possibilidade das companhias em segmentar os seus passageiros e praticar preços de passagens variados aos seus usuários, fomentando a competitividade de seu serviço em relação às outras companhias.

Entre os efeitos da competitividade entre as companhias aéreas, nota-se uma tendência para a prática de descontos no valor de passagens aéreas compradas com antecedência. Em uma rápida consulta de preços nos próprios sites das companhias aéreas é possível encontrar tarifas promocionais para voos com partida entre 30 e 70 dias da data de compra.

O objetivo deste trabalho destina-se em avaliar o comportamento dos preços das passagens aéreas em função da antecedência de compra para os seguintes cenários:

i) Existem efeitos diferentes nos preços dos voo regional e ponte aérea ao considerar a antecedência de compra?

ii) Em meses de alta estação os descontos são maiores nas compras antecipadas?

Para atingir satisfatoriamente o objetivo proposto, o trabalho final foi dividido em três seções. A primeira seção refere-se ao levantamento teórico que trata do assunto de variação dos preços das passagens praticada pelas companhias aéreas.

A segunda seção destina-se ao estudo e análise do efeito da antecedência de compra no preço das passagens aéreas. Foram coletados dados em um período de três anos (2008, 2009 e 2010) 
de voos originários dos aeroportos de Guarulhos e Congonhas, ambos localizados na região metropolitana de São Paulo (RMSP).

Na terceira e última seção são expostos os comentários finais e as conclusões do estudo.

\section{Revisão da literatura sobre a prática de preços das companhias aéreas}

Alguns trabalhos clássicos apresentam evidências sobre a política das companhias aéreas em praticar preços de passagens variados para um mesmo voo. Um dos fatores de grande impacto na variação dos preços abordado pela literatura é o tipo de passageiro em viagem.

Bilotkach (2005) apresenta a segmentação e categorização dos viajantes que optam pelo transporte aéreo. A discussão aqui é se os passageiros a negócio pagam valores mais altos de passagem do que os viajantes comuns (a lazer). Para isso, Bilotkach levanta a hipótese de que as passagens aéreas compradas com pouco tempo de antecedência (na semana do voo, por exemplo) são mais caras ou possuem pouco desconto. Comumente, os passageiros a negócio viajam em resposta a uma demanda de reuniões, o que dificulta um planejamento antecipado assertivo.

Borenstein et al. (1994) consideram que este efeito da variação dos preços por segmentação dos passageiros, pode ser ainda mais perceptível nas rotas de alta competitividade. Este fato evidencia a necessidade em se observar a condição de mercado das companhias aéreas no par aeroporto-cidade em que o serviço de transporte é prestado.

\section{Estudo do efeito da antecedência de compra no preço das passagens aéreas}

\subsection{Apresentação e análise dos dados}

Com o auxílio do site especializado Submarino Viagens, foram coletados cerca de 200.000 dados de passagens aéreas entre os anos de 2008 e 2010. Todas as passagens tinham como origem os aeroportos de Congonhas e Guarulhos, ambos na Região Metropolitana de São Paulo, e destino variados para outras regiões brasileiras (i.e. Sul e Nordeste). 
Além dos aeroportos de origem e destino, foram observados os dados de data e horário da cotação e saída do voo e a companhia aérea prestadora do serviço. Com estas informações, acredita-se que os resultados possam ter alto índice de credibilidade. Os seguintes tópicos tratam da apresentação das principais variáveis analisadas, além do efetivo estudo econométrico.

\subsection{Estudo econométrico}

O estudo econométrico desenvolvido neste trabalho consiste na construção de um modelo reduzido em preço que viabilize o entendimento das possíveis variações nos preços das passagens aéreas em função da antecedência de compra dos bilhetes.

Os dados de entrada do modelo se apresentaram na estrutura de painel de dados. Devido à característica específica do painel em prover uma observação de dois ou mais indivíduos ao longo de um período de tempo (i.e. dados mensais do mercado de transporte aéreo), a obtenção do modelo econométrico consistente foi conduzida com o uso de controles de estimação.

A literatura específica ilustra que o uso de estimadores com controle de efeitos fixos tem sido utilizado em relevantes trabalhos na área de transporte aéreo. Os efeitos-fixos que caracterizam as especificidades de cada um dos indivíduos observados ao longo do tempo. Evans e Kessides (1993), no estudo de efeitos da dominância em pares de aeroportos-cidade no poder de preço das companhias aéreas, utilizam a estimação com efeitos fixos para controlar as peculiaridades de cada par aeroporto-cidade observado. Os resultados das estimações demonstraram validade econômica e estatística significante.

Para o caso do presente estudo, propõem-se um modelo de regressão que pode ser escrito conforme a Equação (1):

$$
\begin{aligned}
& \text { price }=\beta_{1}(\text { adv days })+\beta_{2}(\text { usd })+\beta_{3}(\text { nstop })+\beta_{4}(\text { hday quote })+\beta_{5}(\text { hday dpt })+ \\
& \beta_{6}(\text { fin crisis })+\beta_{7}(\text { delay })+\beta_{8}(\text { azul })+\beta_{9}(\text { conn pax })+\beta_{10}(\text { nairlines } a-\text { pair })+ \\
& \beta_{11}(\text { nairlines adj }- \text { pair })+\beta_{12}(\text { nairlines airp }-o)
\end{aligned}
$$




\subsubsection{Apresentação das variáveis}

Para se estabelecer as relações entre a antecedência de compra e a prática de descontos pelas companhias aéreas, foram estudadas as seguintes variáveis explicativas:

- adv_days: antecedência de compra em relação ao departure date

- usd: cotação do dólar

- advdays_regional: antecedência de compra em relação ao departure date para voos regionais

- advdays_ponteaerea: antecedência de compra em relação ao departure date para ponte aérea

- advalta_*: antecedência de compra em viagens na alta estação

- advbaixa_*: antecedência de compra em viagens na baixa estação

- nstop: voos com escalas ou sem escalas

- hday quote: cotação feita em um dia de feriado

- hday dpt: voo com saída em um dia de feriado

- fin crisis: variável representativa da crise econômica no ano de 2009

- delay: impacto dos atrasos de voos no preço

- azul: efeito de entrada da Azul nos preços da passagens

- conn pax: passagens de voos com conexão

- nairlines a - pair: número de companhias aéreas no par de aeroportos

- nairlines adj - pair: número de companhias aéreas em aeroportos de origem adjacentes (outros aeroportos metropolitanos i.e. Guarulhos e Congonhas)

- nairlines airp - o: número de companhias aéreas no aeroporto de origem 
As variáveis representativas do efeito da antecedência de compra para os voos regionais (advdays_regional) ou ponte aérea (advdays_ponteaerea) derivam da variável de antecedência de compra (adv_days).

A variável de alta estação (advalta_*) foi construída com base nos meses de férias de verão e inverno. Os períodos considerados foram:

- Férias de verão: segunda semana de dezembro à primeira semana de fevereiro.

- Férias de inverno: segunda semana de julho à última semana de julho.

\subsubsection{Especificação do modelo}

Através da Equação (1) buscou-se estimar os impactos de cada uma das variáveis no preço das passagens aéreas.

A Tabela 1 representa os coeficientes estimados com controle de efeitos-fixos. Os principais controles utilizados no modelo foram: par aeroporto-cidade, dia da semana e aeroportohorário.

Enquanto a primeira coluna (Tabela 1) refere-se à estimação do parâmetro, a segunda identifica o desvio padrão da estimação. Nota-se que, com exceção das variáveis de cotação em dias de feriado (hday quote) e do número de companhias em aeroportos adjacentes (nairlines adj - pair), todas as outras estimações foram estatisticamente significantes entre $0.1 \%$ e $1 \%$. O grau de explicação do modelo, dado pelo R-2, demonstra-se estável ao considerar a estrutura de painel dos dados. 
Tabela 1 - Estimação com Efeitos-Fixos

\begin{tabular}{lcc}
\hline \multicolumn{3}{c}{$(1)$} \\
price \\
\hline adv days & $-0.295^{* * *}$ & \\
advdays_regional & $0.052^{* * *}$ & 0.015 \\
advdays_ponteaer & $-0.075^{* * *}$ & 0.013 \\
usd & $35.735^{* * *}$ & 1.197 \\
nstop & $-30.973^{* * *}$ & 0.913 \\
hday quote & -2.064 & 1.112 \\
hday dept & $3.790^{* * *}$ & 1.137 \\
fin crisis & $-2.222^{* *}$ & 0.730 \\
delay & $12.258^{* * *}$ & 1.797 \\
azul & $-2.800^{* * *}$ & 0.590 \\
conn pax & $-36.844^{* * *}$ & 7.410 \\
nairlines a-pair & $-3.633^{* * *}$ & 0.219 \\
nairlines adj-pair & -0.138 & 0.202 \\
nairlines airp-o & $-1.175^{* * *}$ & 0.253 \\
\hline Observations & 219907 & \\
Adjusted R-squared & 0.585 & \\
\hline
\end{tabular}

Standard errors in second column

$* \mathrm{p}<0.05, * * \mathrm{p}<0.01, * * * \mathrm{p}<0.001$

\subsubsection{Análise dos resultados}

Os resultados do modelo econométrico demonstram que a compra antecipada de passagens aéreas possui impacto redutivo nos valores de compra. Os únicos parâmetros que contribuem com o aumento médio dos preços são a data de saída em dia de feriado, os atrasos dos voos e a cotação do dólar (todos estatisticamente significantes).

Para determinar se a compra antecipada de passagens dos voos regionais varia de forma diferente do que para os voos de ponte aérea, devem ser observadas as estimações das variáveis advdays_regional e advdays_ponteaerea, respectivamente.

Como estas duas variáveis derivam da variável adv_days, o impacto real de cada uma na redução dos preços é obtido após a soma das estimações individuais com o coeficiente da variável adv_days, conforme o seguinte:

a) Efeito da antecedência de compra para voos regionais

- 0.295 (estimação da adv_days) +0.052 (estimação da advdays_regional $)=-0.243$

b) Efeito da antecedência de compra para voos de ponte aérea 
- 0.295 (estimação da adv_days) + (-) 0.075 (estimação da advdays_ponteaerea) $=-0.37$

A formulação anterior indica que a compra antecipada resulta em um desconto médio de $24.3 \%$ no preço das passagens dos voos regionais e $37 \%$ no desconto dos voos em ponte aérea.

Esta diferenciação do comportamento dos descontos entre os tipos de voo pode ser explicada pela segmentação dos passageiros. Normalmente, os voos de ponte aérea são utilizados por viajantes a negócio que partem do aeroporto de Congonhas. Este cenário revela uma tendência para a prática de preços mais elevados, principalmente pelo fato das viagens a negócio não serem planejadas com muita antecedência. Por outro lado, os resultados das estimações demonstram que um planejamento antecipado, para qualquer tipo de viajante, pode refletir em bons descontos no valor da passagem aérea.

A Tabela 2 indica as estimações que auxiliam a resposta para a segunda pergunta proposta por este trabalho: Períodos de alta estação possuem maiores descontos nas compras antecipadas?

Os valores de entrada da segunda coluna da Tabela 2 possuem como base de comparação com a compra antecipada em um dia de alta estação. Desta forma, o modelo retrata que, em suma, nos períodos de baixa estação os descontos praticados são maiores. Ao se comparar a compra antecipada em um dia na baixa estação e outro na alta, nota-se que no primeiro caso a passagem pode ser até $17.9 \%$ mais baixa em relação ao segundo. Em compensação, a partir de 30 dias antes do voo, os descontos na alta estação se tornam maiores do que na baixa. 
Tabela 2 - Estimação: Períodos de Alta e Baixa e estação

\begin{tabular}{lll}
\hline & $\begin{array}{c}(1) \\
\text { price }\end{array}$ & \\
\hline advalta_10days & $-34.959 * * *$ & 1.216 \\
advalta_30days & $-49.363 * * *$ & 1.210 \\
advalta_3days & $-10.439 * * *$ & 1.187 \\
advalta_45days & $-52.499 * * *$ & 1.222 \\
advalta_5days & $-20.079 * * *$ & 1.107 \\
advalta_60days & $-53.126 * * *$ & 1.248 \\
advalta_7days & $-32.852^{* * *}$ & 1.187 \\
advbaixa_10days & $-36.862 * * *$ & 1.600 \\
advbaixa_1day & $-17.897^{* * *}$ & 1.966 \\
advbaixa_30days & $-39.146 * * *$ & 1.615 \\
advbaixa_3days & $-31.857^{* * *}$ & 1.674 \\
advbaixa_45days & $-38.645^{* * *}$ & 1.601 \\
advbaixa_5days & $-36.209 * * *$ & 1.658 \\
advbaixa_60days & $-36.752 * * *$ & 1.582 \\
advbaixa_7days & $-35.312^{* * *}$ & 1.595 \\
\hline Observations & 219907 & \\
Adjusted R-squared & 0.597 & \\
\hline
\end{tabular}

Standard errors in second column

* $\mathrm{p}<0.05, * * \mathrm{p}<0.01, * * * \mathrm{p}<0.001$

Mais uma vez estes efeitos podem ser explicados pela categorização dos passageiros. Como apresentado anteriormente, enquanto na alta estação predominam os viajantes a lazer, a baixa estação é marcada por viagens a negócio.

Além disso, a prática do yield management contribui com compreensão do quanto os passageiros estão dispostos a pagar na alta e baixa estação. Sabe-se que no curto prazo (passagens compradas entre 1 e 4 semanas antes do voo) predomina uma demanda mais inelástica ao preço, o que é uma característica dos viajantes a negócio. Em compensação, os viajantes a lazer, mais sensíveis ao preço, possuem mais tempo para o planejamento e compra das passagens. 


\section{Conclusões}

A entrada de companhias com modelos low-cost no mercado brasileiro (Gol - 2001 e Azul 2009) pode ter contribuído com o efeito de popularização do transporte aéreo no país. Somado a este fator, a desregulação do mercado firmada na última década, viabiliza a prática do chamado yield management pelas companhias aéreas.

Neste cenário, abre-se a porta para o desenvolvimento de pesquisas que buscam o entendimento do comportamento dos preços praticados pelas companhias aéreas no Brasil.

Este trabalho faz uso das condições do transporte aéreo na Região Metropolitana de São Paulo (Aeroportos de Guarulhos e Congonhas) para avaliar se existe diferenciação na prática de descontos através da antecedência de compra das passagens em dois casos específicos. $\mathrm{O}$ primeiro caso refere-se à variação dos descontos entre os voos regionais e ponte aérea. No segundo, abordam-se as diferenças de descontos na alta e baixa estação.

Com auxílio de um estudo econométrico observou-se que a antecedência de compra reflete, em média, descontos de até $37 \%$ nos voos de ponte aérea e $24.3 \%$ nos voos regionais. Ao observar os períodos de alta e baixa estação, nota-se que os descontos para compra antecipada na baixa estação são maiores do que na alta nos períodos de curto prazo (até 1 mês). A partir de 30 dias os descontos na alta estação tornam-se maiores.

A principal explicação encontrada para este comportamento dos preços refere-se à segmentação dos passageiros. Passageiros a negócio possuem pouco tempo de planejamento da viagem, o que, quase sempre, resulta em compras de última hora. Porém essa categoria de viajante é mais inelástica ao preço. Em contrapartida, os passageiros que viajam a lazer conseguem descontos maiores no longo prazo, principalmente por terem um planejamento antecipado da viagem e da compra das passagens.

Estes resultados evidenciam o desafio para as companhias aéreas em lançarem os preços das passagens aéreas nos períodos mais adequados. Considerando que ambas as categorias de passageiros possuem disposição a pagar e diferentes sensibilidades ao preço, este desafio torna-se ainda maior e mais dificultoso. 


\section{Referências}

Amorim, H. C. (2007) A Gol ainda é uma Empresa Low-Fare? Journal of Transport Literature, vol. 1, n. 1, pp. 23-45.

ANAC (2010). Anuário do Transporte Aéreo 2009. $2^{\mathrm{a}}$ Ed. Volume Único. Brasília, DF.

Bilotkach, V. (2005). Understanding Price Dispersion in the Airline Industry: Capacity Constraints and Consumer Heterogeneity. Advances in Airline Economics, Vol. 1.

Borenstein, S., Rose, N. L., (1994). Competition and Price Dispersion in the U.S. Airline Industry The Journal of Political Economy, Vol. 102, Issue 4, August 1994.

Evans, W., Kessides, I. (1993). Localized market power in the U.S. airline industry. Review of Economics and Statistics, vol. 75, pp. 66-75.

Ferreira, N. S. (2011) Estudo empírico de práticas predatórias de companhias aéreas. Journal of Transport Literature, vol. 5, n. 3, pp. 89-122.

Fraga, R. e Oliveira, A. V. M. (2009) Distribuição de Slots em Aeroportos: A Experiência Internacional e a Concentração de Frequências de Vôo no Brasil. Journal of Transport Literature, vol. 3, n. 2, pp. 25-46.

INFRAERO (2010). Anuário Estatístico Operacional 2010. Empresa Brasileira de Infraestrutura Aeroportuária, Ministério da Defesa, Brasília, DF.

Lovadine, D. (2009) Análise Econométrica Estrutural da Conduta Competitiva: Estudo de Caso do Transporte Aéreo Pós-Liberalização. Journal of Transport Literature, vol. 3, n. 1, pp. 7-39.

Oliveira, A. V. M. (2010) A Alocação de Slots em Aeroportos Congestionados e suas Consequências no Poder de Mercado das Companhias Aéreas. Journal of Transport Literature, vol. 4, n. 2, pp. $5-49$.

Paiva, I. (2012) Como as conexões de passageiros nos aeroportos de São Paulo afetam as tarifas oferecidas ao paulistano. Journal of Transport Literature, Vol. 6, n.1.

Salgado, L. H., Vassallo, M. D. e Oliveira, A. V. M. (2010) Regulação, Políticas Setoriais, Competitividade e Formação de Preços: Considerações sobre o Transporte Aéreo no Brasil. Journal of Transport Literature, vol. 4, n. 1, pp. 7-48.

Todesco, F., Lovadine, D., Bettini, H. F. e Vassallo, M. D. (2008) Web Pricing de Companhias Aéreas Durante uma Guerra de Preços: Onde estão os Descontos? Journal of Transport Literature, vol. 2, n. 1, pp. 21-38.

Ueda, T. V. A. (2012a) Congestionamento em aeroportos: há alguma saída para o caos? Journal of Transport Literature, Vol. 6, n.2.

Ueda, T. V. A. (2012b) Fusões no transporte aéreo: estudos e tendências. Journal of Transport Literature, Vol. 6, n.4.

Ueda, T. V. A. (2012c) Partir do aeroporto de Congonhas é mais caro que partir de Guarulhos? Um estudo econométrico dos preços das passagens aéreas. Journal of Transport Literature, Vol. 6, n.3.

Vassallo, M. D. (2010) Simulação de Fusão com Variações de Qualidade no Produto das Firmas: Aplicação para o Caso do Code-Share Varig-TAM. Journal of Transport Literature, vol. 4, n. 2, pp. 50-100. 